\title{
Nanostructured Materials for Li-Ion Batteries and Beyond
}

\author{
Xifei Li ${ }^{1,2, *}$ and Xueliang Sun ${ }^{3, *}$ \\ 1 Energy and Materials Engineering Centre, College of Physics and Materials Science, \\ Tianjin Normal University, Tianjin 300387, China \\ 2 Tianjin International Joint Research Centre of Surface Technology for Energy Storage Materials, \\ Tianjin 300387, China \\ 3 Nanomaterials and Energy Lab, Department of Mechanical and Materials Engineering, \\ University of Western Ontario, London, ON N6A 5B9, Canada \\ * Correspondence: xfli2011@hotmail.com (X.L.); xsun@eng.uwo.ca (X.S.); Tel.: +86-22-23766526 (X.L.) \\ Academic Editor: Thomas Nann \\ Received: 5 April 2016; Accepted: 6 April 2016; Published: 7 April 2016
}

This Special Issue "Nanostructured Materials for Li-Ion Batteries and Beyond" of Nanomaterials is focused on advancements in the synthesis, optimization, and characterization of nanostructured materials, with an emphasis on the application of nanomaterials for building high performance Li-ion batteries (LIBs) and future systems. The nanostructured materials permit high contact area of the battery's active materials with its electrolyte and shorten the ion diffusion path, which reveals obvious advantages, increasing the system's performance. As a result, researchers have continued their dedication in searching for new, facile, low-cost synthetic routes toward novel nanostructured materials and exploring their application in LIBs, Li-S batteries, aqueous batteries, and supercapacitors. The nanostructures employed in this Special Issue include: nanocoatings, nanorods, mesoporous materials and more. An overview of various syntheses and electrochemical performance of these innovative nanostructured materials is further discussed.

High performance $\mathrm{Si}$ anodes suffer from large volume change upon cycling in LIBs. Hwang et al. [1] reported the structural, mechanical, and electronic properties of graphite-like amorphous carbon coating on bulk silicon to improve the durability of the $\mathrm{Si}$ anode using molecular dynamics simulations and ab-initio electronic structure calculations. Chen et al. [2] studied $\mathrm{Li}_{4} \mathrm{Ti}_{5} \mathrm{O}_{12}$ (LTO)/Si composites with different weight ratios. It can be found the electrodes with moderate Si content deliver a stable capacity with good cycling performance, even at a very high current density. The improvement in specific capacity and rate performance was a direct result of the synergy between LTO and Si. Focusing on the cathode, the nanostructured $\mathrm{LiCoPO}_{4}$ designed by Manzi and co-workers [3] illustrated the effect of different $\mathrm{Co}^{2+}$ sources, solution acidity, and reaction times on the crystal growth of the $\mathrm{LiCoPO} 4$ particles by means of a multi-technique approach. Moreover, lithium-excess and nano-sized $\mathrm{Li}_{2+x} \mathrm{Mn}_{1-x / 2} \mathrm{TiO}_{4}(x=0,0.2,0.4)$ cathode materials synthesized via a sol-gel method by Zhang et al. [4] revealed that the charge-discharge performance of the nanostructured material was improved remarkably with increasing lithium content.

The design of various morphologies is also presented in this issue. For example, Das et al. [5] have studied the numerical simulation of LIBs with the anode made of core-shell heterostructures of silicon-coated carbon nanofibers. Sun et al. [6] performed a facile hydrothermal strategy using an $\mathrm{H}_{2} \mathrm{O}$ solvent for the large-scale preparation of finger-like $\mathrm{Co}_{3} \mathrm{O}_{4}$ nanorods. Chang et al. [7] demonstrated the application of various sizes of ordered mesoporous carbon nanospheres with diameters of 46-130 nm as active anode materials for LIBs. The facile synthesis of various morphologies might be one of the most promising strategies for high-performance anode materials.

With a low redox potential and a high specific capacity, bismuth was demonstrated as a suitable anode material for aqueous batteries. As part of Zuo and co-workers' efforts in this area, a bismuth 
electrode film was directly grown by a facile hydrothermal route and tested in $\mathrm{LiOH}, \mathrm{NaOH}$ and $\mathrm{KOH}$ electrolytes [8]. It was found that, with a smaller $R_{\mathrm{s}}$ and faster ion diffusion coefficient, a Bi electrode film in $\mathrm{KOH}$ electrolyte exhibited better electrochemical performance. Song et al. [9] designed a freestanding Si-Ti-Ni (STN) alloy particle/reduced graphene oxide/single wall carbon nanotube composites film. The performance improvements were attributed to the suppression of the pulverization of the STN active material by the excellent mechanical properties of the reduced graphene oxide-single wall carbon nanotube networks and the enhanced kinetics associated with both electron and $\mathrm{Li}$ ion transport.

In this issue, special attention is also paid to important systems beyond LIBs. For example, Ye et al. [10] found that the introduction of CTAB changes the speciation of $\mathrm{S}$ in the $\mathrm{Li} / \mathrm{S}$ cathode dramatically due to the interaction of CTAB with the terminal $S$ atoms of the polysulfide ions in the $\mathrm{Na}_{2} \mathrm{~S}_{x}$ solution. For the cycled Li/S cell, during the charge/discharge processes, the capacity fade was shown to be due to the loss of electrochemically active sulfur and the accumulation of a compact insulating layer of unexpected sulfur reaction products on the cathode surface. In addition, Liu et al. [11] successfully obtained nitrogen-doped banana peel-derived porous carbon as a binder-free electrode for supercapacitors. Their results exhibited a high performance including a high specific surface area of $1357.6 \mathrm{~m}^{2} / \mathrm{g}$, large pore volume of $0.77 \mathrm{~cm}^{3} / \mathrm{g}$, a suitable mesopore size distributions around $3.9 \mathrm{~nm}$, and super hydrophilicity due to the nitrogen-containing functional groups.

Due to the advantages of delivering more than one electron, multivalent systems have gained considerable attention. Meanwhile, considering the increasing demand for high energy density batteries and improved safety, in their review article, Guduru and co-workers [12] presented a brief overview of recent progress of multivalent intercalation batteries, including electrode chemistries, functionalities and challenges. Particular attention was paid to $\mathrm{Al}$-ion batteries. $\mathrm{Al}^{3+}$ is smaller than $\mathrm{Li}^{+}$ in the unsolvated state, but its strongest electrostatic bonding nature with the host electrode materials, similar to many other di- and tri-valent ions, usually results in slower diffusion kinetics within the electrodes. Despite this, it has been found to intercalate/deintercalate into/from certain compounds exhibiting good electrochemical characteristics for battery applications.

In summary, the papers published in this Special Issue provide recent developments of nanostructured active materials in the area of LIBs and future systems. We highly recommend reading this Special Issue, and look forward to your own journal contributions in this fascinating field in the years ahead.

Conflicts of Interest: The authors declare no conflict of interest.

\section{References}

1. Hwang, J.; Ihm, J.; Lee, K.-R.; Kim, S. Computational evaluation of amorphous carbon coating for durable silicon anodes for lithium-ion batteries. Nanomaterials 2015, 5, 1654-1666. [CrossRef]

2. Chen, C.; Agrawal, R.; Wang, C. High performance $\mathrm{Li}_{4} \mathrm{Ti}_{5} \mathrm{O}_{12} / \mathrm{Si}$ composite anodes for Li-ion batteries. Nanomaterials 2015, 5, 1469-1480. [CrossRef]

3. Manzi, J.; Curcio, M.; Brutti, S. Structural and morphological tuning of $\mathrm{LiCoPO}_{4}$ materials synthesized by solvo-thermal methods for Li-cell applications. Nanomaterials 2015, 5, 2212-2230. [CrossRef]

4. Zhang, X.; Yang, L.; Hao, F.; Chen, H.; Yang, M.; Fang, D. Lithium-excess research of cathode material $\mathrm{Li}_{2} \mathrm{MnTiO}_{4}$ for lithium-ion batteries. Nanomaterials 2015, 5, 1985-1994. [CrossRef]

5. Das, S.; Li, J.; Hui, R. Simulation of the impact of Si shell thickness on the performance of Si-coated vertically aligned carbon nanofiber as Li-ion battery anode. Nanomaterials 2015, 5, 2268-2278. [CrossRef]

6. Sun, S.; Zhao, X.; Yang, M.; Ma, L.; Shen, X. Facile and eco-friendly synthesis of finger-like $\mathrm{Co}_{3} \mathrm{O}_{4}$ nanorods for electrochemical energy storage. Nanomaterials 2015, 5, 2335-2347. [CrossRef]

7. Chang, P.-Y.; Bindumadhavan, K.; Doong, R.-A. Size effect of ordered mesoporous carbon nanospheres for anodes in Li-ion battery. Nanomaterials 2015, 5, 2348-2358. [CrossRef]

8. Zuo, W.; Xu, P.; Li, Y.; Liu, J. Direct growth of bismuth film as anode for aqueous rechargeable batteries in $\mathrm{LiOH}, \mathrm{NaOH}$ and $\mathrm{KOH}$ electrolytes. Nanomaterials 2015, 5, 1756-1765. [CrossRef] 
9. Song, T.; Choi, J.; Paik, U. Freestanding rGO-SWNT-STN composite film as an anode for Li ion batteries with high energy and power densities. Nanomaterials 2015, 5, 2380-2390. [CrossRef]

10. Ye, Y.; Kawase, A.; Song, M.-K.; Feng, B.; Liu, Y.-S.; Marcus, M.; Feng, J.; Cairns, E.; Guo, J.; Zhu, J. $\mathrm{X}$-ray absorption spectroscopy characterization of a Li/S cell. Nanomaterials 2016, 6, 14. [CrossRef]

11. Liu, B.; Zhang, L.; Qi, P.; Zhu, M.; Wang, G.; Ma, Y.; Guo, X.; Chen, H.; Zhang, B.; Zhao, Z.; Dai, B.; Yu, F. Nitrogen-doped banana peel-derived porous carbon foam as binder-free electrode for supercapacitors. Nanomaterials 2016, 6, 18. [CrossRef]

12. Guduru, R.; Icaza, J. A brief review on multivalent intercalation batteries with aqueous electrolytes. Nanomaterials 2016, 6, 41. [CrossRef]

(C) 2016 by the authors; licensee MDPI, Basel, Switzerland. This article is an open access article distributed under the terms and conditions of the Creative Commons by Attribution (CC-BY) license (http://creativecommons.org/licenses/by/4.0/). 